\title{
Controversies on Hypothermia in Cardiac Arrest
}

\section{Cenker Eken}

Department of Emergency Medicine, Akdeniz University Faculty of Medicine, Antalya, Turkey

The American Heart Association guidelines on resuscitation have recently come out. Hypothermia between $32^{\circ} \mathrm{C}$ and $34^{\circ} \mathrm{C}$ was recommended as a Class I indication in the 2010 guidelines for shockable rhythms. The resuscitation council referred to two articles that were published in NEJM in 2002 for this robust recommendation. The Targeted Temperature Management (TTM) trial that came out in 2013 had contrary findings compared with those of these previous articles. Despite the results of the TTM trial, the resuscitation council preferred to keep the recommendation level as Class I rather than lowering it (1). Although it has been retained as Class I, the recommended body temperature recommended is in the range of $32^{\circ} \mathrm{C}-36^{\circ} \mathrm{C}$. This might be related to the intention of not stepping back rather than scientific concerns.

Taking a glance at pioneering articles that underpinned the 2010 guidelines for hypothermia may lead to a comprehensive insight on the issue. The first trial was a small study by Bernard et al. (2). They conducted a quasi-randomized trial in patients who had a spontaneous return of circulation following a cardiac arrest due to ventricular fibrillation (VF). The intervention was cooling the patients at $33^{\circ} \mathrm{C}$ for 12 hours (h). The favoring neurological outcome was $49 \%$ in intervention group and $26 \%$ in control group $(p=0.046)$. The second trial was by the "Hypothermia After Cardiac Arrest Group," in which over 250 patients were enrolled, and this trial had a larger sample size than the first (3). The authors studied hypothermia defined as $32^{\circ} \mathrm{C}-34^{\circ} \mathrm{C}$ for $24 \mathrm{~h}$ in patients who had return of spontaneous circulation (ROSC) following VF. Favoring neurological outcome assessed by the Pittsburgh cerebral performance scale was reported to be $55 \%$ in the intervention group and $39 \%$ in the control group ( $p=0.009$ ). The findings of these two trials have been cited for stating hypothermia as a Class I recommendation in patients who have ROSC following VF arrest.

Robust data regarding hypothermia in cardiac arrest patients has been presented by the TTM trial that came out in 2013 (4). It had been conducted in 36 intensive care units in Europe and Australia and has recruited over 900 patients. The TTM trial compared $33^{\circ} \mathrm{C}$ vs. $36^{\circ} \mathrm{C}$ that can also be defined as normothermia. The authors recruited all patients either with shockable or non-shockable rhythms except unwitnessed patients with an initial rhythm of asystole. Poor neurological outcome
(Modified Rankin Scale score of 4-6) was the same in both groups (52\% vs $52 \%$, respectively) and was $54 \%$ in the hypothermia group and $52 \%$ in the control group when assessed by the Cerebral Performance Category of $3-5(p=0.78)$. Despite the lack of subgroup analysis reporting the neurological outcome for shockable rhythms, mortality rates were $40.8 \%$ in the hypothermia group and $39.7 \%$ in the control group for patients who had an initial shockable rhythm.

The detailed analysis of the studies and meta-analysis on the issue are available in the current issue of the Eurasian Journal of Emergency Medicine (5). A classical phenomenon has been posed in hypothermia trials that studies with a small sample size are prone to misleading effects of random error and chance factor. Random error indicates the effect of heterogeneity factor on the results and findings of small studies. Studies with small sample sizes might have fluctuating results and will be closer to the real values when more patients are recruited; this can be explained by the law of large numbers. The first two trials composed the basics of the recommendation in 2010 had approximately 350 patients, and the TTM trial brought out the unfavorableness of performing robust recommendations using the findings of small trials rather than waiting for more powered ones.

\section{References}

1. Callaway CW, Donnino MW, Fink EL, Geocadin RG, Golan E, Kern KB, et al. Part 8: Post-Cardiac Arrest Care: 2015 American Heart Association Guidelines Update for Cardiopulmonary Resuscitation and Emergency Cardiovascular Care. Circulation 2015; 132(Suppl 2): S465-82. [CrossRef]

2. Bernard SA, Gray TW, Buist MD, Jones BM, Silvester W, Gutteridge G, et al. Treatment of Comatose Survivors of Out-of-Hospital Cardiac Arrest with Induced Hypothermia. N Engl J Med 2002; 346: 557-63. [CrossRef]

3. Hypothermia after Cardiac Arrest Study Group. Mild therapeutic hypothermia to improve the neurologic outcome after cardiac arrest. $\mathrm{N}$ Engl J Med 2002; 346: 549-56. [CrossRef]

4. Nielsen N, Wetterslev J, Cronberg T, Erlinge D, Gasche Y, Hassager C, et al. Targeted temperature management at $33^{\circ} \mathrm{C}$ versus $36^{\circ} \mathrm{C}$ after cardiac arrest. N Engl J Med 2013; 369: 2197-206. [CrossRef]

5. Eken C. Hypothermia in Cardiac Arrest: A Meta-analysis and Evidence Based Appraisal of the Current Data. Eurasian J Emerg Med 2015; 14: 164-6.

Correspondence to: Cenker Eken e-mail: cenkereken@gmail.com

Received: 18.11.2015 Accepted: 20.11.2015

(C) Copyright 2015 by Emergency Physicians Association of Turkey - Available online at www.eajem.com DOI: $10.5152 /$ eajem.2015.58224 